\title{
Os sentidos atribuídos pelas crianças à cidade*
}

\author{
The meanings attributed by children to the city \\ Las nociones atribuídas por los niños a la ciudad \\ VANIA CARVALHO DE ARAÚJO*** \\ LuCIANA Pimentel RHOdES GONÇALVES SOARES*** \\ ROSALI RAUTA SILLER ${ }^{* * * *}$ \\ INES DE OLIVEIRA RAMOS ${ }^{* * * * *}$ \\ VICTÓRIA GALTER VIEIRA****** \\ ÉRIKA MILENA DE SOUZA*******
}

\begin{abstract}
$\diamond$
RESUMO

Este artigo expõe parte do resultado de um estudo exploratório realizado com 220 crianças de dez cidades do Estado do Espírito Santo matriculadas nas instituições de educação infantil. Tem por objetivo discorrer sobre os sentidos atribuídos pelas crianças à cidade, evidenciando alguns constrangimentos pelos quais elas passam em função de serem excluídas do planejamento da cidade e dos espaços sociais mais amplos. As narrativas das crianças expõem o paradoxal movimento entre a invisibilidade das crianças e a capacidade de as culturas infantis inaugurarem novos dispositivos discursivos que permitam construir outras racionalidades. Considerar as diferentes formas de simbolização das crianças acerca de seus mundos de vida é perceber que elas carregam consigo as marcas das culturas dos adultos, ao mesmo tempo em que são capazes de empreender outros sentidos sobre a realidade, o que deixa transparecer um universo de significação peculiar sobre a cidade, cujas sutilezas constituem um patrimônio social próprio das culturas infantis, ainda que em plena articulação com as culturas adultas.
\end{abstract}

Palavras-chave: Crianças e cidade. Educação infantil e cidade. Cidade e infância.

\begin{abstract}
This paper shows part of the results of an exploratory study performed with 220 children from ten cities of the State of Espírito Santo registered in the institutions of childhood education. It aims at discussing the meanings attributed by the children to the city, highlighting some constraints by which they pass due to being excluded from the city planning and from the broader social spaces. Children's narratives reveal the paradoxical movement between the invisibility of children and the capacity of children's cultures to launch new discursive devices that allow to build other rationalities about their experience with the city. To consider the different ways of symbolization of children is to perceive that they carry with them the marks of adult's culture, at the same time that they are able to undertake other meanings about reality, what reveals a universe of peculiar meaning about the city, whose subtleties constitute a social legacy appropriate to children's cultures, even in full articulation with adult's cultures.
\end{abstract}

Keywords: Children and city. Children education and city. City and childhood.

\section{RESUMEN}

Este artículo expone parte del resultado de un estudio exploratorio realizado con 220 niños de diez ciudades del Estado de Espírito Santo matriculados en instituciones de educación infantil. Tiene por objetivo discutir sobre las nociones atribuidas por los niños a la ciudad, evidenciando algunas restricciones por las que pasan en función de ser excluidos de la planificación de la ciudad y de espacios sociales más amplios. Los relatos de los niños exponen

*Pesquisa financiada pela Fundação de Amparo à Pesquisa e Inovação do Espírito Santo (Fapes).

**Doutora e Pós-doutora em Educação pela USP. Professora do Programa de Pós-Graduação em Educação - PPGE/UFES. Coordenadora do Grupo de Pesquisa "Infância, Educação, Sociedade e Cultura - IESC". <https://orcid.org/0000-0002-7678-1689>. E-mail: <vcaraujoufes@gmail.com>.

*** Mestre em Educação pela UFES. Professora do Ensino Básico, Técnico e Tecnológico - CEI Criarte/UFES. <https://orcid.org/0000-0002-1890-6690>. E-mail: <lucianaprgs@gmail.com>.

****Doutora em Educação pela Unicamp. Pós-doutoranda em Educação pela UFES. Pedagoga da Rede Pública Estadual - SEDU/ES. <https://orcid. org/0000-0002-5296-8908>. E-mail: <rauta13@gmail.com>.

*****Doutora e Pós-Doutora em Educação pela UFES. Professora Adjunta do Departamento de Teorias do Ensino e Praticas Educacionais do Centro de Educação da UFES. <https://orcid.org/0000-0003-2019-8600>. E-mail: <inesram.ufes@gmail.com>.

******Graduada em Pedagogia pela UFES. Professora de Educação Infantil. <https://orcid.org/0000-0003-2475-1223>. E-mail: victoria-galter@ hotmail.com>.

*******Doutora em Educação PPGE/UFES. Professora de Ciências SEME/PMV. <https://orcid.org/0000-0002-6298-3378>. E-mail: <erikamilenasouza@ gmail.com>. 
el paradójico movimiento entre la invisibilidad de los niños y la capacidad de las culturas infantiles de inaugurar nuevos dispositivos discursivos que permiten construir otras racionalidades sobre su experiencia con la ciudad. El considerar las diferentes formas de simbolización de los niños es percibir que éstas cargan consigo las marcas de las culturas de los adultos, al mismo tiempo que son capaces de emprender otros sentidos sobre la realidad, lo que deja traslucir un universo de significado peculiar sobre la ciudad, cuyas sutilezas constituyen un patrimonio social propio a las culturas infantiles, aunque en plena articulación con las culturas adultas.

Palabras clave: Niños y ciudad. Educación infantil y ciudad. Ciudad e infancia.

\section{INTRODUÇÃo}

Em suas crônicas sobre a cidade, João do Rio narra um tempo em que da janela se podia observar, apreciar, encantar, recusar o que se passava na rua. Nesse quadro humano absolutamente exposto, revela sua alma, "a alma encantadora das ruas":

Oh! sim, as ruas têm alma! Há ruas honestas, ruas ambíguas, ruas sinistras, ruas nobres, delicadas, trágicas, depravadas, puras, infames, ruas sem história, ruas tão velhas que bastam para contar a evolução de uma cidade inteira, ruas guerreiras, revoltosas, medrosas, spleenéticas, snobs, ruas aristocráticas, ruas amorosas, ruas covardes, que ficam sem pinga de sangue (DO RIO, 2008, p. 34).

Paradoxalmente, observa a decomposição das ruas, onde faz emergir um novo tipo de metrópole sob a representação de novas feições do espaço urbano e com ele novos usos e costumes da e na cidade vão se delineando. Assim, João do Rio, com uma sensibilidade estranha ao seu próprio tempo, consegue capturar "a alma encantadora das ruas" e observar a derradeira destruição de imagens até então disponíveis, cujas janelas começam a fechar-se e, por meio delas, não é mais possível capturar o frenesi dos acontecimentos humanos, pois a ameaça da cidade moderna, voltada à presentificação do tempo e à mercantilização da vida, faz verter olhares para a própria intimidade e preocupações privadas.

Em nome da modernidade, não só a rua, mas toda a cidade sofre contínuos processos de desqualificação que justificam, sob o ponto de vista da civilização e do progresso, novas formas de ordenamento e de segregação social. É nesse sentido que a urbis vai se transformando em um espaço "fetichizado" em função de realidades fragmentárias e, como uma mercadoria, vai servindo de utensílio às trocas humanas justapostas pelos distanciamentos, disputas e acirramentos. Martins (2008, p. 193) ressalta: "A realidade urbana é aberta para novos investimentos de capital, mas crescentemente fechada para a criação de relações sociais não mediadas pelas coisas. A valorização das coisas se dá à custa da desvalorização do homem". Santos (1997, p. 22), por sua vez, destaca que
“[...] os progressos de nossa infeliz civilização conduzem mais e mais a uma sociedade atomizada por um espaço que dá a impressão de reunir".

É justamente nesse modo de perceber que, à proporção que as cidades crescem e a distância entre os homens aumenta, se configura uma realidade paradoxal do espaço urbano, pois o espaço que une, é o espaço que separa os homens (SANTOS, 1997). Se a cidade dos nossos dias perdeu suas referências estáveis e tranquilizadoras (PORTELLA, 2012) e tornou-se uma cidade em cuja conspiração da modernidade trafegam mercadorias, projetos, desejos individualizados e um presente petrificado ou, como diria Innerarity (2006, p. 106), ao observar os efeitos da concentração dos centros comerciais e industriais, "[...] um arquipélago urbano sem cidade, uma sucessão aleatória de aglomerados", outra cidade insiste em sobreviver no decurso de uma experiência muitas vezes rarefeita pela própria invisibilidade que a acompanha.

Tal como João do Rio, abrimos janelas com o objetivo de observar o inaudito da cidade, capturar algumas de suas franjas marginais, confrontando os discursos plasmados por uma retórica adulta de que a cidade não pertence às crianças, já que ela perdeu seus referenciais clássicos da experiência. Contudo, não queremos apenas abrir janelas para observar a cidade, mas nos aproximarmos das crianças para melhor compreender suas experiências na e sobre a cidade, onde e como brincam, do que mais gostam e menos gostam do lugar onde moram, enfim, quais os sentidos que atribuem à cidade, reconhecendo que "[...] o olhar das crianças permite revelar fenômenos sociais que o olhar dos adultos deixa na penumbra ou obscurece totalmente" (PINTO; SARMENTO, 1997, p. 25).

Discorrer sobre os sentidos atribuídos pelas crianças à cidade é uma possibilidade de expor alguns constrangimentos pelos quais elas passam em função de serem excluídas do seu planejamento e dos espaços sociais mais amplos. Nesse processo, novos enunciados dão conta de expor o movimento entre a invisibilidade das crianças e a capacidade de as culturas infantis inaugurarem novos dispositivos discursivos que permitam construir outros sentidos sobre a cidade, o que nos leva a afirmar que, embora suas narrativas sejam interpeladas por um universo cultural globalizado, as culturas infantis revelam 
uma capacidade peculiar de se inscrever no mundo e de se expressar.

A questão que se coloca é: "[...] até que ponto e de que forma o interesse da criança encontra-se representado" (QVORTRUP, 2015, p. 19) no planejamento e nos diferentes territórios da cidade? Vale destacar o que aponta a Carta das Cidades Educadoras proposta em Barcelona, em novembro de 2004: "[...] as cidades grandes ou pequenas dispõem de inúmeras possibilidades educadoras, mas podem ser igualmente sujeitas a forças e inércias deseducadoras". Ao discorrer sobre a importância de considerar a presença das crianças na cidade, Silva (2011, p. 270) sublinha: "São exigentes as responsabilidades que se abatem sobre os gestores do espaço, sobretudo urbano, para que não fechem as oportunidades que um planejamento plástico não deixará de propiciar no sentido do acolhimento de estratégias que tornem o chão também territorializável no interesse das crianças".

Considerar as diferentes formas de interpretação das crianças sobre a cidade é perceber que elas carregam consigo as marcas das culturas dos adultos, ao mesmo tempo em que são capazes de empreender outras formas de representação sobre a realidade, o que deixa transparecer um universo de significação peculiar sobre a cidade, cujas sutilezas constituem em patrimônio social próprio das culturas infantis, ainda que em plena articulação com as culturas adultas. Assim, "A interpretação das culturas infantis não pode ser realizada no vazio social, e necessita de se sustentar na análise das condições sociais em que as crianças vivem, interagem e dão sentido ao que fazem" (SARMENTO; PINTO, 1997, p. 22).

Em nossa trajetória de pesquisa, que ora passamos a apresentar alguns de seus resultados, duas escolhas foram fundamentais ao processo de investigação: uma delas deuse quando priorizamos meninos e meninas com idades de cinco anos matriculados nas instituições públicas de educação infantil. Além da idade, a diversidade de gênero constituiu-se uma variável importante com vistas a alargar a variedade de dados, mesmo se, na análise das respostas das meninas e dos meninos, foram observadas grandes similitudes. Além disso, o encontro com as crianças no contexto das instituições possibilitou uma recolha das informações mais detalhadas dos diferentes grupos sociais ali representados.

As cidades pesquisadas, em sua grande maioria, pertencem às diferentes regiões do interior do Estado do Espírito Santo, ${ }^{1}$ o que permitiu encontrar, em uma mesma

\footnotetext{
1 Para a seleção dos dez municípios, foi considerada a caracterização aplicada pelo Governo do Estado do Espírito Santo na definição das microrregiões e macrorregiões do Estado (Lei Estadual no 9.768/2011). Para a escolha das instituições de educação infantil, levamos em conta a sua localização no contexto urbano e no contexto rural, conforme indicação da Secretaria de Educação.
}

instituição, crianças de diferentes classes sociais, devido à inexistência ou à inexpressiva oferta de instituições privadas de educação infantil nos contextos investigados em relação à oferta das instituições públicas de educação infantil. ${ }^{2}$ Embora a indicação das instituições tenha sido de responsabilidade das Secretarias Municipais de Educação, o encontro com as crianças deu-se do modo mais informal possível, isso porque era necessário nos fazer conhecer e explicar a elas os motivos da pesquisa, sem prescindir das peculiaridades de se fazer pesquisa com crianças.

Outra escolha importante ao processo de pesquisa foi a necessidade de romper com uma visão homogênea e urbana de cidade, considerando que a vida de campo continua sendo marginalizada por nem sempre reunir adjetivos convergentes com a tecnologia do progresso e com o consumo. A definição de rural e urbano ainda se apresenta fluida na realidade brasileira, pois são várias características que atravessam tal compreensão, seja pela composição das edificações, da economia, das paisagens etc., seja pela densidade demográfica. Mesmo não tendo consenso entre os pesquisadores (INEP, 2006), consideramos, para efeito de localização das instituições, a caracterização dada às escolas pelas respectivas Secretarias de Educação.

A proposta era entrevistar 12 crianças com idades de cinco anos (seis meninos e seis meninas) de uma única turma. Embora muitas delas tivessem interesse em participar, chegado o momento da entrevista, não quiseram mais sair da sala de aula, ora porque não viam muito entusiasmo no retorno de seus companheiros entrevistados, ora porque continuavam intimidadas com a nossa chegada. Porém, parte signifcativa das crianças atendeu ao convite e, espontaneamente, elas foram conosco para um lugar mais adequado para conversarmos, de modo que a opinião de um não influenciasse a opinião do outro. Das 240 crianças inicialmente previstas para as entrevistas, 220 crianças foram efetivamente os sujeitos do estudo exploratório.

Procuramos organizar as questões de modo a não constranger ou cansar as crianças, pois também era necessário tempo adequado para estabelecermos um diálogo a partir do que desejavam expor, o que pensam, já que, em diferentes momentos, a complexidade de algumas de suas argumentações exigia uma maior atenção e compreensão, mediante sucessivas analogias e um conjunto de gestos e dispositivos colocados em prática no momento da elaboração de suas opiniões às questões apresentadas.

\footnotetext{
2 Dos dez municípios pesquisados, cinco não possuem instituições privadas de educação infantil (creche ou pré-escola). Enquanto as instituições públicas são 287 , as privadas são um total de 41 , portanto a diferença entre elas é de $75 \%$.
} 
Propusemos três eixos de investigação para a elaboração das perguntas e posterior análise de suas respostas, a saber: a) os sentidos que as crianças atribuem à cidade; b) os diferentes modos de habitar da criança em contextos urbano e/ou rural; c) a caracterização da cidade sob o ponto de vista da utilização dos seus espaços pelas crianças. Enquanto os dois primeiros eixos dependiam de um contato mais direto com as crianças, a caracterização da cidade, a partir das referências por elas indicadas, exigiu uma maior aproximação dos pesquisadores de alguns contextos sociais e culturais das cidades investigadas. Assim, por meio de um trabalho de campo, as observações proporcionadas pela câmara fotográfica ampliaram a área de percepção (SOUZA; LOPES, 2002) sobre os lugares mencionados pelas crianças onde brincam e aqueles supostamente instituídos para elas brincarem, como as praças e os parques públicos existentes.

Assim, conhecer melhor o entorno das instituições onde as crianças passam grande parte de suas vidas nos permitiu identificar algumas tensões e possibilidades de

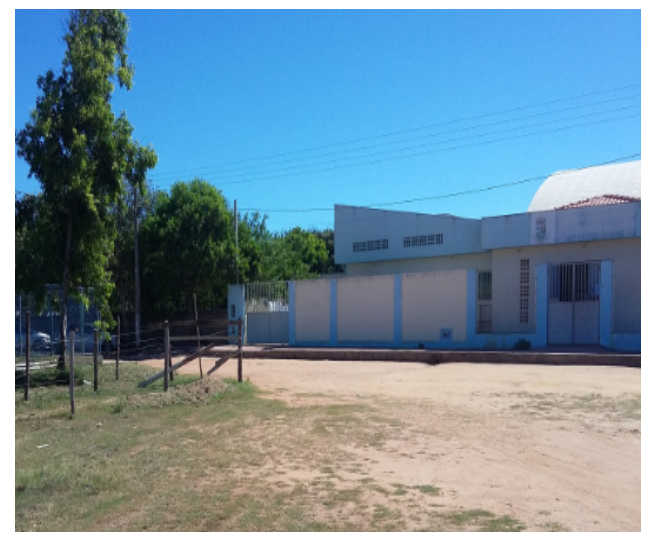

Figura 1. Localização da escola

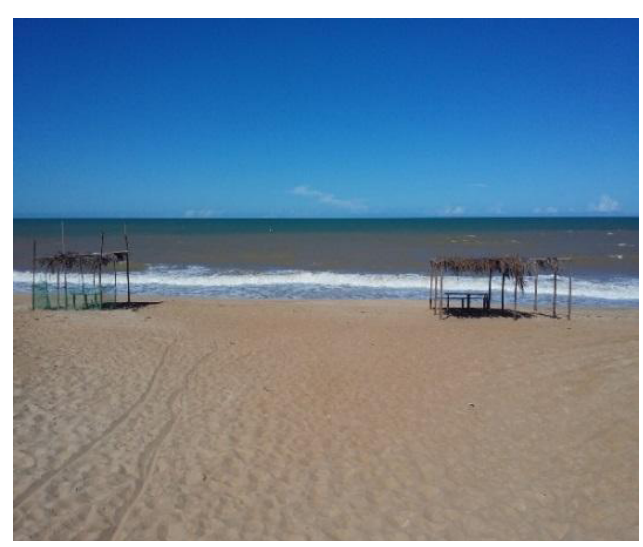

Figura 2. Praia localizada próxima à escola diálogo entre a escola e o seu exterior. Dependendo do significado que o "estar dentro" e "o estar fora" assumia, as crianças tinham a escola como uma única referência de espaço para brincar durante as atividades escolares ou eram motivadas a fazer uso dos espaços próximos à instituição como parte integrante da experiência educativa, conforme podemos ilustrar abaixo nas duas instituições localizadas em contextos rurais nas microrregiões Rio Doce e Noroeste, respectivamente.

Como um lugar que exige demasiada atenção por parte da professora, a praia não foi capaz de interditar seu uso pelas crianças, assim como um simples equipamento de madeira com forma diminuta de um parque também tem servido como um dispositivo lúdico para elas. Como pudemos observar, nas duas instituições de educação infantil investigadas, o entorno tem possibilitado criar nichos de experiências de forma diferente daquelas instituições cujos equipamentos, com condições mais satisfatórias, restringem a circulação e utilização por parte das crianças, fazendo sobressair pouca interação com seu contexto exterior.

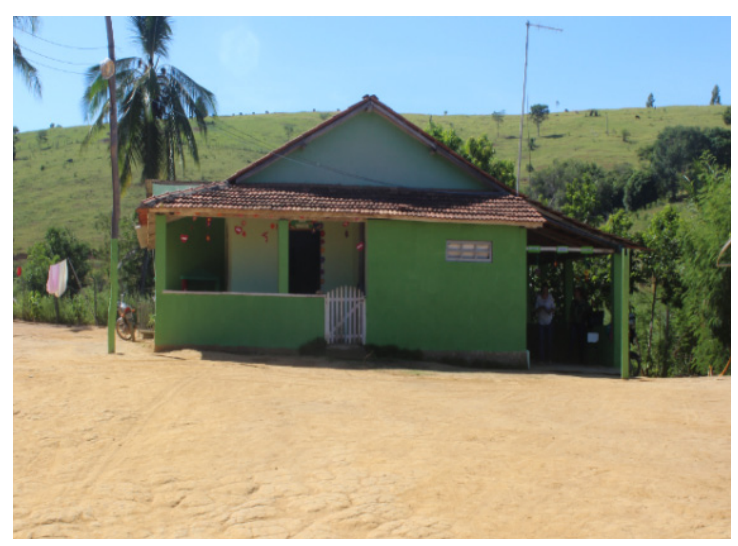

Figura 3. Espaço utilizado pelas crianças no entorno da escola

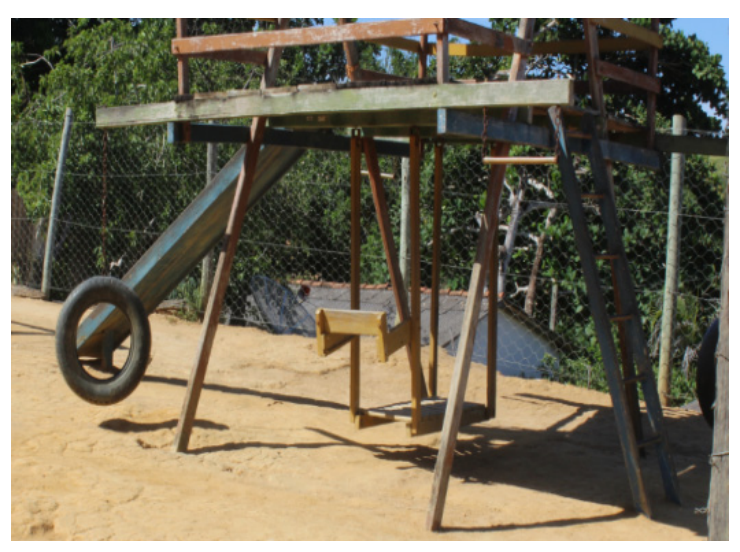

Figura 4. Balanços localizados ao lado da escola 
Por meio das fotografias, foi possível observar que os ambientes externos às instituições ainda não constituem referências importantes para o trabalho educativo, tornando efêmero tudo aquilo que está disposto para além de seus muros e grades. Parafraseando Souza (2001), muros e grades forçam as escolas e os diferentes espaços da cidade a serem vistos como outro lugar, longe das condições históricas que os fizeram aparecer ali e longe de sua dimensão pública. Mayumi Lima (1989), ao discorrer sobre as diferentes formas de apoderamento dos espaços das crianças pelos adultos, transformando-os em instrumento de dominação, chama a atenção para o quanto as instituições escolares e os profissionais da arquitetura se utilizam da insegurança, dos perigos da rua e da posição negativa que a cidade frequentemente assume no imaginário social como artifícios para manter as crianças como expectadoras do seu meio ambiente.

\begin{abstract}
A insegurança não diz respeito apenas ao medo de que crianças fiquem expostas a possíveis perigos, pois estes são reais e podem ser controlados objetivamente; o medo maior é o do desconhecido, do novo que pode surgir na ação das crianças e que pode colocar-nos diante da necessidade de nos repensarmos enquanto profissionais, enquanto pessoas que dominam o saber e, portanto, o poder (LIMA, 1989, p. 39).
\end{abstract}

Nas imagens abaixo, uma repetição dos critérios de edificação é um exemplo de como as crianças e a necessária interação da escola com o seu entorno não são levadas a efeito em contextos sociais distintos, seja nas cidades interioranas, seja naquelas localizadas na região metropolitana. A disposição arquitetônica nos fornecem algumas pistas de como as escolas ganham um sentido privado, reclusas que estão da paisagem externa. Ladeadas por muros e grades, seus espaços externos se transformam em lugar de passagem e, quando muito, em um território ameaçador e obsoleto para outros tipos de experiências educativas.

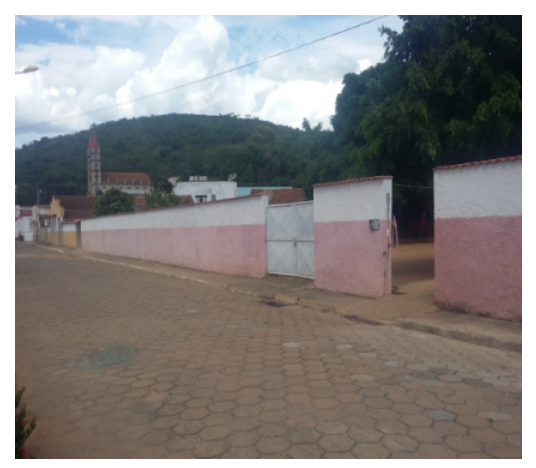

Figura 5. Espaço externo à escolamicrorregião Central-Serrana

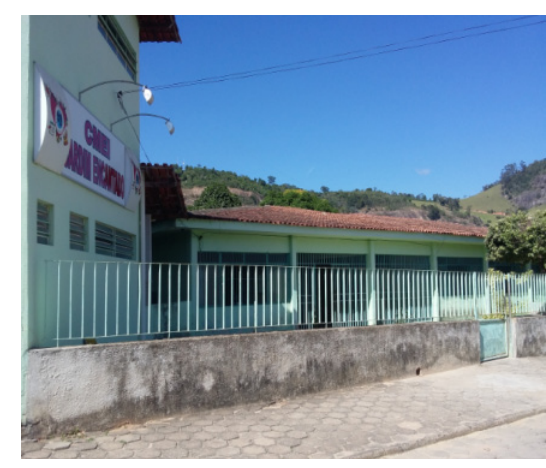

Figura 6. Espaço externo à escolamicrorregião Noroeste
Conforme destacam Souza e Lopes (2002, p. 64), "É preciso aprender a olhar o mundo indo aos detalhes, melhor dizendo, decompor o mosaico para melhor enxergar a figura que reina majestosa no todo de uma revelação figurativa". Se, no estudo exploratório realizado, não foi possível decifrar todas as particularidades que as imagens fotográficas nos despertaram, ao menos nos ajudou a tomar consciência sobre o quanto elas têm a nos revelar e o quanto desencadeiam outras possibilidades estéticas, éticas e analíticas na busca dos sentidos que procuramos capturar. No processo de compreender as narrativas das crianças por meio também das imagens, aspectos desafiadores da cidade, em relação às culturas infantis, foram identificados ao tempo em que as imagens nos ajudaram a ultrapassar nosso próprio enquadramento (SOUZA; LOPES, 2002), desencadeando outras formas de compreender a realidade, ampliando o olhar para a multiplicidade de seus acontecimentos.

\section{O QUE DIZEM AS CRIANÇAS: ALGUMAS ANÁLISES}

Ao analisar as experiências narradas pelas crianças nos espaços e tempos das cidades pesquisadas, percebemos que elas situam suas experiências no âmbito do viver, remetendo-se aos vínculos afetivos estabelecidos com familiares, com a própria casa, com a casa dos "outros" - amigos, igreja e arredores. Quando questionadas sobre o que mais gostam do lugar onde moram, elas não se referiram diretamente a um espaço físico, mas a uma experiência vivida e, mesmo quando algumas recorreram a um espaço socialmente demarcado (casa dos amigos, da tia, do avô, a igreja, outra cidade) deixaram transparecer um tipo de experiência que fazem na cidade e o sentido que atribuem às relações nela tecidas, tais como: gostam de estar sozinhas com outras crianças, da liberdade de brincar, da alegria por estar em outro lugar etc. Esses sentidos ganham centralidade em 
suas falas não simplesmente porque fazem parte de sua rotina, mas por que expressam relações estabelecidas por meio de vínculos afetivos e/ou por situações marcadas por desejos, expectativas e/ou necessidades.

O brincar aparece como um recurso predominante, apresentando-se como o grande fluxo de pertencimento a um lugar que, mesmo desprovido de sua representação objetivável, está impregnado de relações de prazer, companheirismo, cumplicidade e afetividade. Mais do que remeter-se a um lugar socialmente demarcado, o brincar, como demonstração de uma escolha e medida de pertencimento, expõe outras formas de referenciar-se ao "lugar" onde moram, dixando-o transparecer como um espaço de vida, de memória e de infância. É na possibilidade do encontro entre as crianças que o brincar se mostra mais revelador de seu sentido; sentido que só quem o experencia é capaz de expressar.

As crianças conseguem também expor certo grau de descontentamento quando o vazio social de um espaço torna impotente sua utilização e impossível outra significação para além do que ele deixa transparecer, por exemplo, em um contexto cujo território é ocupado por extensas lavouras de abacaxi. Esse espaço, impossível de ser habitado pelas crianças, traduz o legado de que a terra, ocupada pelo oligopólio da produção, nada mais oferece às novas gerações do que uma paisagem opaca e rotineira. Ali o "campo" deixou de ser um espaço brincante e transformou-se numa tediosa visão da monocultura do abacaxi. ${ }^{3}$ Desejar morar na "cidade" passa a ser a enunciação de um lugar diferente, uma possibilidade de novas experiências, em contraponto com um território marcado por sua própria desumanização, já que nele a arte do conviver e do coabitar é muito mais reduzida.

Tais enunciados tornam-se também presentes em suas narrativas sobre o que menos gostam do lugar onde moram. Independentemente dos contextos onde vivem: rurais ou urbanos, poucas remetem a um lugar específico, mas às impressões primeiras de suas experiências, pois realidades culturais consideradas antagônicas tornam-se portadoras de sentidos comuns sobre aquilo que não gostam do lugar onde moram: carne amassada $(\mathrm{R}) ;{ }^{4}$ do mosquito da dengue (U); peixe com espinho (R); de jambos amargos $(\mathrm{R})$; da igreja, porque demora muito a acabar $(\mathrm{U}) ;$ da chuva, porque alaga a rua (U); da galinha, porque está cheia de piolho $(\mathrm{R})$; do capim grande, porque atrapalha a jogar bola (R); de tomar banho na praia quando está frio (U); de ficar em casa (U); quando minha irmã não me deixa jogar no quarto dela (U). Os vínculos estabelecidos

\footnotetext{
${ }^{3}$ No Espírito Santo, a área cultivada de abacaxi é de aproximadamente 4.640 hectares. Na cidade pesquisada, a área cultivada é de 2.800 hectares, sendo o terceiro maior produtor de abacaxi do Brasil e o primeiro da variedade pérola.

${ }^{4}$ (R) Rural e (U) Urbano.
}

em relação à cidade parecem constituir-se mais pelo que temem ou lhes indigna do que por uma integração positiva (INNERARITY, 2006). Uma ressemantização da cidade precisa ser considerada, pois as narrativas das crianças não constituem uma realidade exterior às suas condições reais de existência; ao contrário, elas indicam uma presença ativa das crianças nos diferentes contextos que frequentam ou onde habitam.

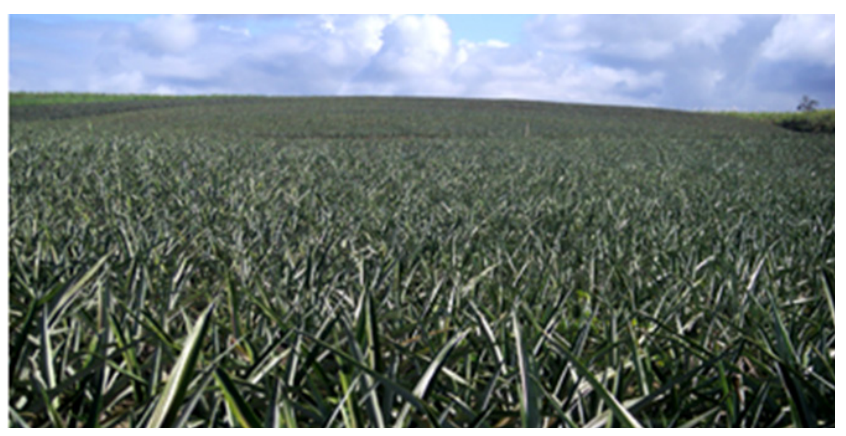

Figura 8. Plantação de abacaxi na microrregião Litoral Sul

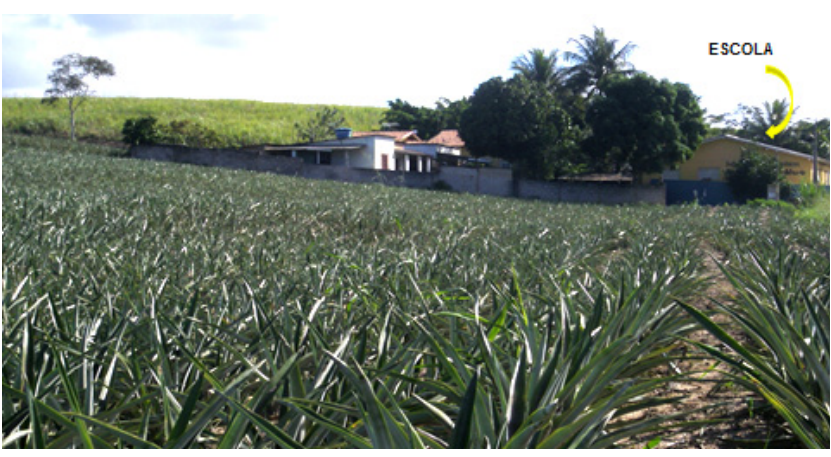

Figura 9. Localização da escola

Fonte (Figs. 8-9): Arquivo Grupo de Pesquisa IESC/2017.

Quando questionadas sobre o que é uma cidade, enquanto a maioria das respostas das crianças indica que elas não sabem, um percentual significativo refere-se à rua. Rua e cidade revelam-se como termos equivalentes, contudo essa equivalência não aparece de modo fortuito nas falas das crianças, ela está fortemente influenciada pelo modo como os adultos expõem os acontecimentos da rua na cidade. Mas a rua assim como a cidade podem também representar o modo como a criança vê esse espaço a partir de suas experiências no espaço público e das influências que os meios de comunicação exercem no imaginário social. Cabe ressaltar que não foram exigidas às crianças respostas mais "adequadas" sobre o que é uma cidade, acrescendo à pergunta outras formas mais inteligíveis de compreensão. $\mathrm{O}$ fato de a maioria das crianças não conseguir definir o que é uma cidade pode demonstrar o quanto a cidade ainda prefigura como uma realidade estranha a muitas crianças 
ou que a pergunta, tal como elaborada, não foi passível de compreensão para algumas delas.

Indagadas sobre o que tem numa cidade, "casa" tornou-se o recurso mais frequente para as crianças moradoras do contexto urbano. Porém, nas narrativas das crianças do campo, sapo, cobra, cavalo, cabrito e plantas aparecem como componentes importantes. Nesse caso, a estruturação de seus mundos de vida no campo é transmutada como cidade, o que deixa entrever que, para as crianças, não existe um sentido único e homogêneo de cidade, pois tais sentidos dizem respeito também às impressões primeiras de suas práticas sociais e culturais vividas.

Ao considerarmos todas as respostas sobre o que tem numa cidade, destacam-se os lugares por elas vividos (a própria cidade, praia, lagoa, roça), lugares por elas conhecidos (outras cidades, lugarejos) e lugares por elas concebidos como edificações (casas, prédios, apartamentos, escola, hospital, igreja, praças, parquinhos, rua), estabelecimentos comerciais (lojas, supermercados, shopping, padaria etc.), elementos da natureza (árvores, pedras, areia, folhas, flores, rio, animais), pessoas (familia, criança, policial), brinquedos (bonecas, panelinhas, Barbie). Além disso, apontam outras informações, cujas propriedades, mesmo distintas entre si, estão relacionadas com a composição de uma cidade, como comida, feijão, doce, frutas, leite, sorvete, semáforo, dengue e placas de trânsito.

Embora, nas análises, tais informações se apresentem discriminadas por temáticas afins, as impressões primeiras das crianças sobre o que existe em uma cidade se misturam às suas diferentes práticas, expressando, assim, um variado espectro de informações. Dessa forma, “[...] afirma-se o lugar social das crianças como sujeitos que desestabilizam, desfocam e descentram olhares adultos, que provocam e remetem os adultos a tocar em suas memórias e experiências" (DEBORTOLI, 2008, p. 80).

A partir de um olhar prospectivo voltado à apreensão do significado que a criança atribui à cidade, perguntamos: Se você pudesse construir uma cidade, como ela seria? Ao discorrerem sobre como seria essa cidade, as crianças a imaginam composta por diferentes elementos que dizem respeito a edificações (casas, prédios, ruas, uma casa para eu morar, ia fazer um castelo), ao uso de veículos (carros, motos, ônibus, bicicletas, caminhões), ao acesso a alimentos e guloseimas (morangos, comida, feijão, arroz, carne, pão, doces, frutas, sorvete, chips, rosquinha de chocolate, cheia de bala), à existência de estabelecimentos comerciais e lugares de entretenimento (shopping, lojas de roupas, lojas de brinquedos, supermercados, lanchonetes, cinema, parque aquático, loja de chapéu, ia fazer um castelo, um lugar para todo mundo dançar, ia ter roça), a determinados brinquedos (carrinho, bonecas, muitos brinquedos, bola, bicicleta, pula-pula), a equipamentos e espaços públicos (cidade com balanços e escorregador, com muitas pracinhas e parquinhos, muitas escolas, playground, balanços, roda-roda). Um grupo significativo de crianças remete a elementos da natureza (teria muitas flores, plantas $e$ cheia de jardins, cheia de árvores, cheia de passarinhos e borboletas, seria cheia de peixes e tartarugas, lagoa, com cavalos). Outras criam um universo particular para a construção da cidade (seria um lugar para todo mundo dançar, teria um Papai Noel, seria mágica, todo mundo brincando juntos, sem perigo).

É possível inferir que as crianças imaginam a cidade a partir das suas experiências concretas de vida e das expectativas que criam por meio de diferentes dispositivos, sejam eles reais, sejam imaginários. Sarmento (2004, p. 26) destaca que nas culturas infantis, o processo de imaginação do real é "[...] fundacional do modo de inteligibilidade. Esta transposição imaginária de situações, pessoas, objetos ou acontecimentos [...] está na base da constituição da especificidade dos mundos da criança [...]”.

Ao discorrerem sobre como seria uma cidade por elas construída, as crianças ressaltam que teria faixa de pedestre, serviços de saneamento básico, esgoto, encanação e também poderia oferecer comida, feijão, arroz, carne, pão e área de lazer com parques e campo de futebol. Porém, mais do que esses espaços públicos criados e delimitados, em sua grande maioria, elas revelam suas preferências pelos espaços abertos, em contato com os elementos da natureza: com muito verde, cheia de flores, árvores, matos e com animais, como cavalos, passarinhos, borboletas, cachorros, gatos, onde as experiências de correr, agachar, esconder, pular, subir e também a convivência estabelecida com os "outros" - outras crianças, outros jovens outros adultos, outros idosos - possam acontecer com liberdade e em ambientes comuns a todos.

Quais os lugares que as crianças não podem e quais podem frequentar? Essa questão expõe uma intricada relação das narrativas das crianças com a racionalidade adulta, sobretudo quando a rua aparece como o lugar que as crianças não podem frequentar e os parques e praças deixam transparecer uma idealização sobre os lugares que podem frequentar, já que, nas cidades observadas, poucos espaços públicos são disponibilizados para brincadeiras. $\mathrm{Se}$ as crianças definem a rua como cidade e a apontam como um lugar onde elas não podem frequentar, tais enunciados nos instigam a problematizar: em que medida a rua, como imagem definidora da cidade, tem se tornado uma constante ameaça ou um espaço impróprio à presença das crianças? Não estar na rua pode acenar para uma ausência de significações partilhadas entre as crianças na cidade, ao menos em seus espaços considerados públicos. O "perigo das ruas" faz com que as crianças percam seu espaço de convívio entre seus pares e outros grupos geracionais e se isolem em suas casas ou próximo a elas. 
Em pesquisa realizada em um dos bairros de classe popular localizado na cidade de Vitória/ES, Araújo $(2008)^{5}$ identificou alguns paradoxos existentes em torno da rua que, além de constituir-se em um espaço de sociabilidades entre os moradores, de trocas afetivas entre adultos e crianças, de brincadeiras e de amizades, configura-se também como um lugar do perigo, da ameaça e da vagabundagem. Essa imagem contraditória da rua ora definida pelas marcas presentes na oralidade de seus moradores, ora demandada como uma espacialidade a ser econômica, moral e socialmente organizada, faz propagandear uma materialidade discursiva sobre a rua evocando velhas fórmulas generalizantes e excludentes. Assim, a rua, ao mesmo tempo em que se revela como a única possibilidade de brincadeiras coletivas em um contexto capturado pela escassez de espaços comuns, transforma-se no lugar da anomia e da desconfiança, fazendo da escola um arauto da segurança e da moralidade pública.

É curioso observar que a destituição do espaço público, no qual a cidade perdeu seu "sentido comunal" (PEREIRA, 2013), não se faz imperceptível aos olhos das crianças, pois o fato de não indicarem, com frequência, espaços comuns de convivência, praças ou parques não constitui uma referência corrente. Sua existência ou não existência não faz nenhuma diferença, pois, tal como um elemento estático e sem sentido, eles têm servido mais como um lugar de passagem e uma paisagem opaca, pela precariedade de seus espaços, do que como um dispositivo de sociabilidades entre crianças e crianças e entre crianças e adultos.

Essa questão pode ter relação com o pouco incentivo dado à utilização das praças e parques em algumas das cidades observadas. Tais equipamentos, muitas vezes desgastados pelo tempo e pela escassez de sua utilização, completa o mosaico citadino com a exposição estática de suas flagrantes formas monofuncionais que nem sempre permitem às crianças reinventar o seu uso, por se apresentarem apenas como um cenário a mais na cidade. É o que foi identificado em alguns parques instalados: as mesmas cores, as mesmas formas de materiais expostos ao tempo, tornando visível o seu caráter indistinto, previsível, disciplinador e rotineiro, dando a impressão de um parque já pronto para as crianças se adequarem. Mas é curioso que a maioria das crianças não descrevem os parques como um lugar onde elas mais brincam. Estão ali, interditando, de alguma maneira, as possibilidades de as culturas infantis se mostrarem presentes. Crianças e parques estão submetidos às regras de um determinismo urbano que pouco interessa a uma cultura pública democrática.

\footnotetext{
5 Por meio de um estudo de caso do tipo etnográfico, foi possível observar que, embora a representação da rua esteja fortemente influenciada por um discurso socialmente aceitável, tal representação entra em contradição com a apropriação positiva que fazem dela em seu cotidiano.
}

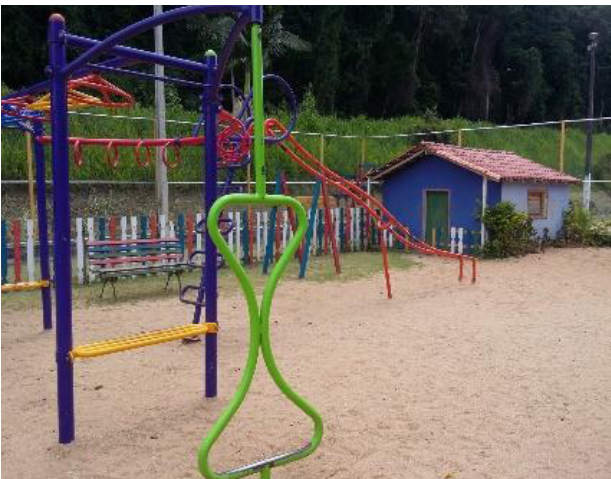

Figura 10. Parque localizado na microrregião Serrana

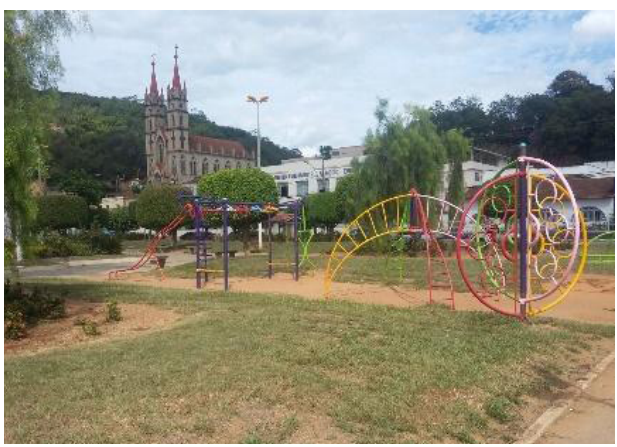

Figura 11. Parque localizado na microrregião Central-Serrana

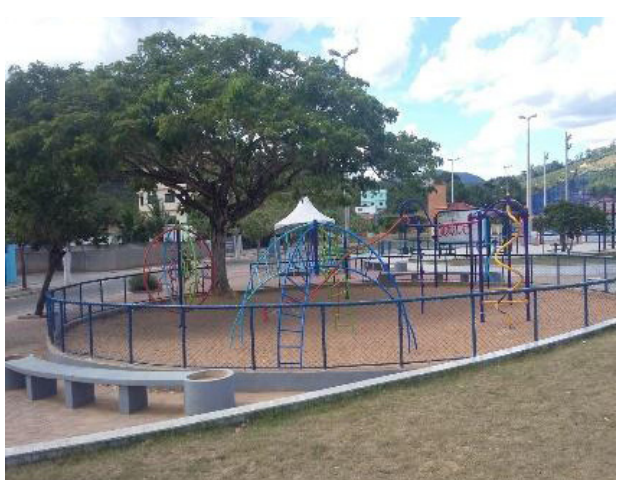

Figura 12. Parque localizado na microrregião Centro-Oeste

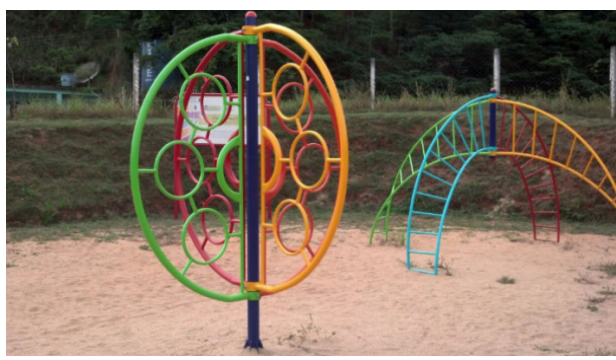

Figura 13. Parque localizado na microrregião Caparaó Fonte (Figs. 10-13): Arquivo Grupo de Pesquisa IESC/2016. 
O que nos chama a atenção, para além dos enquadramentos impostos aos espaços supostamente "brincantes", é que as crianças continuam sendo destinatárias das decisões da administração pública sobre a localização desses espaços e suscetíveis às possibilidades ou não de seu uso, pois dependem de uma série de condições climáticas, segurança e proteção para uma efetiva interação com os equipamentos que, a priori, deveriam estar à sua disposição e mais bem planejados, seja em função de suas características físicas, ${ }^{6}$ seja em função de sua localização na cidade. Além disso, a disponibilidade de tais equipamentos não leva em conta os diferentes contextos de vida das crianças, já que há reprodução de um mesmo modelo de escorregador, trepatrepa, escadinhas etc. em cidades com características geográficas, culturais e sociais distintas.

Uma nova configuração urbana parece influenciar as cidades, em cujas características interioranas de tempos atrás era possível observar uma experiência comum e pública mais frequente. A complexidade da vida e os efeitos de uma sociedade "fatalizada pela ordem das urgências" (MATOS, 2009), carente, portanto, de uma philia social, transmuta os espaços públicos - praças, ruas, parques e praias -, como lugar do risco e, por vezes, um lugar funcional e institucionalizado das brincadeiras.

Onde você brinca? Onde as outras crianças brincam? Enquanto a maioria diz brincar no território da própria casa (quarto, quintal, varanda etc.) e na casa de parentes, ao referirem-se às outras crianças, apontam as suas casas e a escola. Embora, nesse caso, a escola não apareça como o lugar de maior recorrência, ela constitui um espaço importante de brincadeiras e encontros entre as crianças, principalmente nos contextos rurais, cuja convivência com seus pares se torna muito mais restrita em função da ausência de espaços públicos comuns e da distância entre as residências, muitas vezes localizadas em pequenas propriedades. Contudo, ao situarem a escola como um lugar de brincadeiras, as crianças lhe atribuem um sentido como um dispositivo cultural e social importante para a constituição de novas redes de relações entre elas.

Quando a pergunta se volta para: quais os lugares favoritos na cidade?, a casa dos parentes (avós, tios primos) aparece com maior recorrência, demarcando um deslocamento experiencial das crianças para além dos espaços fixos do seu cotidiano. Essa é uma variável de análise social importante a ser considerada na interpretação das culturas infantis e nas suas interações com a cidade. Sair da própria casa e ir para a casa de parentes é um modo de nomear a experiência na cidade que se forma por

\footnotetext{
${ }^{6} \mathrm{Na}$ sua grande totalidade, os materiais dos parques são de ferro, o que impossibilita seu uso de forma contínua por parte das crianças em função de seus efeitos com a quentura do Sol.
}

meio de uma teia de relações e não necessariamente pelos espaços que aludem uso de objetos ou de equipamentos públicos, usualmente identificados como formas e lugares próprios de brincar.

Contudo, outro modo de interpretação pode ser levado a efeito, considerando as respostas das crianças. A casa dos parentes também parece constituir-se um desejo pouco realizável, o que pode gerar surpreendentes expectativas por parte das crianças. Aqui dependeria de uma análise mais aprofundada sobre a frequência com que vão à casa dos parentes (primos, tios, avós) e por que a elegem como o lugar mais favorito na cidade, ainda que possamos entrever que, nesse intercâmbio de experiências, afetos, amizades e boas lembranças tornam-se características importantes em suas escolhas.

As respostas das crianças também indicam praças, parques e praias como um dos lugares favoritos na cidade. Ao que nos parece, não obstante o acesso às praias, principalmente nas cidades litorâneas investigadas, as praças e parques conservam uma imagem naturalizada do lugar onde as crianças brincam ou deveriam brincar. Isso porque a maioria dos equipamentos identificados não agrega uma presença constante e significativa das crianças em função de seus materiais estarem em permanente exposição ao Sol, o que dificulta a sua utilização. Além disso, não há uma cultura pública, a exemplo de muitas cidades brasileiras, de "ocupação" pelas crianças das praças e parques, seja sozinhas, seja acompanhadas de algum adulto. Como a pergunta dirigida foi sobre "os lugares favoritos na cidade", suas respostas, necessariamente, podem não dizer respeito à própria cidade, mas a algum lugar cujas praças e parques assumem outra significação.

Todavia, o que nos chama a atenção é a surpreendente preferência que a casa dos parentes assume nas narrativas das crianças. Isso revela o quanto a busca pela funcionalidade da cidade com seus dispositivos de "brincadeiras" pode estar se sobrepondo a outras formas mais expressivas de interação das crianças com a cidade. A casa dos parentes parece significar novas teias de relações que se articulam em torno da amizade, da afetividade, da arte do encontro entre gerações, expressando formas de sociabilidades pouco visíveis e muitas vezes restritas à esfera da própria casa.

Ao exporem suas preferências, as crianças chamam a atenção para a necessidade de criação de outras ordens relacionais na cidade tão importantes quanto as que resultam do encontro com outras pessoas que gostam. Provavelmente, visitar, brincar ou estar em outra casa pode significar uma maior liberdade, proteção e uma convivialidade que se estabelece fora da sua rotina diária. Sabemos muito bem o que da memória somos capazes de extrair da rica convivência com primos, tios e avós, 
em que era possível apreender outras formas de viver a infância mediante relações recíprocas. As diferentes formas representacionais das crianças não têm ressonância no processo de ressignificação da cidade. Extrair de suas narrativas os sentidos que atribuem à cidade ajuda a expor o fosso ainda aberto entre as prerrogativas dadas pela Administração Pública e a forma marginal com que as culturas infantis são consideradas no processo de reinvenção da cidade, além da necessária criação de espaços mais comuns de existência e de relações éticas e estéticas mais estáveis entre crianças e adultos.

\section{CONSIDERAÇõES FINAIS}

Embora consideradas um grupo marginal nos processos definidores da cidade, as crianças representam uma categoria geracional importante a considerar, seja pela sua representatividade como grupo populacional, seja pelo modo com que interpelam a sociedade como demandantes de novos direitos. Se a costumeira presença das crianças na cidade é desprovida de significação social e deixa de ser percebida como um acontecimento político importante para a comunidade, é porque a própria cidade perdeu seu sentido comunal, como espaço de significação e objetivos partilhados. Ouvir as narrativas das crianças torna-se indispensável para compreender melhor o inaudito da cidade que se apresenta por meio delas, ao tempo em que coloca em xeque a capacidade de nossa sociedade de tomar as crianças e as culturas infantis como referências importantes para se pensar a cidade como um empreendimento comum a todos, portanto, um espaço de coabitação cidadã.

Ao colocarmos em evidência os sentidos atribuídos pelas crianças à cidade, fomos surpreendidas por um conjunto de interpretações e enunciados que desvelam o modo peculiar com o qual as crianças constroem e desconstroem discursos e práticas normalmente produzidos pela racionalidade adulta. Se o recrudescimento dos espaços públicos limita, cada vez mais, as possibilidades de circulação das crianças nos diferentes tempos e espaços sociais, o modo como se apropriam desses espaços e lhes atribuem sentido indica o quanto são capazes de formular conceitos, tendo como referência os próprios constrangimentos e as possibilidades de ação e interação em seus diferentes contextos de vida. Tais reflexões nos levam a inferir que, se as culturas da infância são pouco visíveis aos contextos urbanos e rurais, é porque a cidade ainda não se reconheceu como um suporte social importante para a vida em comunidade.

Sem tomar como modelo uma experiência ocorrida na antiguidade, mas considerando como referência o seu legado como um espaço cívico do bem comum, a pólis, tal como os gregos a definiam, era um ideal de participação e renovação de um mundo comum e público (ARAÚJO, CARVALHO, 2017). A dimensão ética e política da pólis tinha nas virtudes públicas (amizade, hospitalidade, justiça, concórdia etc.) um código de conduta moral que todos deveriam almejar. Recuperar o espírito empreendido pelos gregos em relação à pólis, como a forma mais elevada do convívio humano, ajuda-nos a problematizar a cidade contemporânea, ou ao menos a perceber seus constrangimentos e suas possibilidades como instância de mediação societária entre crianças, jovens e adultos.

Conforme Innerarity (2006, p. 121), "[...] a ideia de cidade sintetiza muito bem o conceito de sociedade que está em jogo". Desse modo, podemos afirmar que não basta garantir formas mais participativas para as crianças sem as prerrogativas de uma cultura democrática na qual suas opiniões e razões possam ser reconhecidas como um atributo definidor da consciência pública da cidade. Os efeitos da cidade fragmentada foram notórios nas falas das crianças. Inscrever outras formas discursivas e práticas capazes de converter a cidade impessoal e sem memória em um artifício humano material e simbólico passa pelo reconhecimento das crianças como atores sociais com capacidade de interpretar e agir no mundo. Daí a necessária superação "[...] dos estereótipos rotineiros e inúteis" (PROUT, 2010, p. 37) sobre as crianças na cidade.

Reconhecer as crianças como participantes ativas nos diferentes espaços da cidade, em contexto urbano e/ou rural, implica considerá-las como categoria geracional e populacional importante num mundo que ainda se apresenta hostil às suas capacidades expressivas e de interpretação. Uma necessária reinvenção da cidade como possibilidade do humano e de sua constituição como uma philia social (ARAÚJO, 2017), tendo as crianças e as culturas infantis como uma expressão mobilizadora de seu sentido e existência, significa pospor a indiferença e a inferioridade as quais as crianças ainda estão submetidas, de modo que suas demandas e aspirações possam ser reconhecidas nas suas próprias razões e legitimidade.

Ouvir as crianças sobre os sentidos que atribuem à cidade coloca-se como um percurso importante para pensarmos a cidade, seus sentidos para a vida em comunidade e o que dela podemos apreender e aprender em sua companhia. As crianças "[...] possuem modos diferenciados de interpretação do mundo e de simbolização do real, que são constitutivos das 'culturas da infância', as quais se caracterizam pela articulação complexa de modos e formas de racionalidade e ação" (SARMENTO, 2005, p.371). Respeitar e levar em consideração as crianças como sujeitos importantes na constituição de uma experiência pública compartilhada confere outra dignidade à cidade, pois se, nos termos de uma sociabilidade regida pela pluralidade humana, 
as diferenças devem encontrar ressonância na vida em comunidade, excluir as crianças dos vínculos sociais mais amplos é privar a infância de determinadas experiências e subordiná-la a regimes discursivos que nada contribuem para o seu reconhecimento público.

\section{REFERÊNCIAS}

ARAÚJO, V. C.; CARVALHO, J. S. F. As possibilidades de uma experiência compartilhada entre adultos e crianças na cidade. Revista Pro-posições, Campinas, v. 28, supl. 1, p.111-131, set./dez. 2017.

ARAÚJO, V. C. de. Educação infantil em tempo integral: em busca de uma philia social. Educar em Revista, Curitiba, n. 63, p. 191-203, jan./maio 2017.

ARAÚJO, V. C. de. Rua e escola: lugares de possíveis compartilhamentos? Cadernos de Pesquisa em Educação, v. 14, n. 28, p. 80-101, jul./dez. 2008.

DEBORTOLI, J. A. O. Imagens contraditórias da infância: crianças e adultos na construção de uma cultura pública coletiva. In: DEBORTOLI, J. A. O.; MARTINS, M. F. A; MARTINS, S. (Org.). Infâncias na metrópole. Belo Horizonte: UFMG, 2008. p. 71-86.

INSTITUTO NACIONAL DE ESTUDOS E PESQUISAS EDUCACIONAIS ANÍSIO TEIXEIRA (INEP). A educação no Brasil rural. Brasília, DF: Inep, 2006.

INNERARITY, D. O novo espaço público. Lisboa: Editorial Teorema, 2006.

LIMA, Mayumi Souza. A cidade e a criança. São Paulo: Nobel, 1989.

MARTINS, S. Urbanização e violência: reflexões a partir do livro e do filme Cidade de Deus. In: DEBORTOLI, J. A. O.; MARTINS, M. F. A.; MARTINS, S. Infâncias na metrópole. Belo Horizonte: UFMG, 2008. p. 175-202.

MATOS, Olgária. Contemporaneidades. São Paulo: Nacional, 2009.

PAYER, M. O. O rural no espaço público urbano. In: ORLANDI, E. P. (Org.). Cidade atravessada: os sentidos públicos no espaço urbano. Campinas, SP: Pontes, 2001.

PEREIRA, P. C. Urbanidade e consciência do comum: para uma apresentação. In: PEREIRA, P. C. (Org.). Espaço público: variações críticas sobre a urbanidade. Porto: Afrontamento, 2013. p. 7-15.
PORTELLA, E. Homem, natureza, cidade. Rio de Janeiro: Tempo Brasileiro, 2012.

PROUT, A. Participação, políticas e as condições da infância em mudança. In: MULLER, F. Infância em perspectiva: políticas, pesquisas e instituições. São Paulo: Cortez, 2010. p. 21-41.

QVORTRUP, J. A dialética entre a proteção e a participação. Currículo sem Fronteiras, v. 15, n. 1, p.11-30, jan./abr. 2015. Disponível em: <http://www.curriculosemfronteiras.org/ vol15iss1 articles/qvortrup.htm.pdf>. Acesso em: 6 set. 2016.

DO RIO, João. A alma encantadora das ruas: crônicas. São Paulo: Companhia das Letras, 2008.

SANTOS, M. Pensando o espaço do homem. São Paulo: Hucitec, 1997.

SARMENTO, M.; PINTO, Manuel. As crianças e a infância: definindo conceitos, delimitando o campo. In: PINTO, M.; SARMENTO, M. As crianças: contexto e identidade. Braga: Centro de Estudos da Criança/Universidade do Minho, 1997. p. 9-30.

SARMENTO, M. J. Gerações e alteridade: interrogações a partir da sociologia da infância. Educação e Sociedade, Campinas, v. 26, n. 91, p. 361-378, maio/ago. 2005.

SARMENTO, M. J. As culturas da infância nas encruzilhadas da $2^{a}$ modernidade. In: SARMENTO, M.; CERISARA, A. B. Crianças e miúdos: perspectivas sociopedagógicas sobre infância e educação. Porto: Edições Asa, 2004. p. 9-34.

SILVA, A. N. Jogos, brinquedos e brincadeiras: trajectos intergeracionais. Vila Verde/Portugal: Atahca, 2011.

SOUZA, S. J.; LOPES, A. E. Fotografar e narrar: a produção do conhecimento no contexto da escola. Cadernos de Pesquisa, n. 116, p. 61-68, jul. 2002. Disponível em: $<$ http://publicacoes. fcc.org.br/ojs/index.php/cp/article/view/582/581>. Acesso em: 1 o dez.2017.

SOUZA, p. de. Espaços interdidatos e efeitos-sujeito na cidade. In: ORLANDI, E. p.(Org.). Cidade atravessada: os sentidos públicos no espaço urbano. Campinas, SP: Pontes, 2001.

Recebido em 24.04.2018

Aprovado em 01.07.2018

Endereço para correspondência

Vania Carvalho de Araújo

Universidade Federal do Espírito Santo - Ufes

Centro de Educação/Programa de Pós-Graduação em Educação

Av. Fernando Ferrari, 514 - Campus Universitário - Goiabeiras 29075-910 Vitória, ES, Brasil 